\title{
Geographical perspectives on location for location based services
}

Edwardes, A J

\begin{abstract}
In this position paper the question of how location is employed in location based services (LBS) is considered. The importance of the notion of location is highlighted as a means of blurring the boundary between forms of experiences that are direct, and sensed in the environment, and those that are indirect, and learned from information. It is suggested that current methods for modeling location are limited by their lack of strong theoretical underpinning. To help bridge this gap the notions of Space, Place, and Region, from geographical theory, are proposed and implications of these for considering location in LBS outlined.
\end{abstract}

DOI: https://doi.org/10.1145/1507136.1507141

Posted at the Zurich Open Repository and Archive, University of Zurich

ZORA URL: https://doi.org/10.5167/uzh-25646

Book Section

Accepted Version

Originally published at:

Edwardes, A J (2009). Geographical perspectives on location for location based services. In: Wilde, E. Proceedings of the 2nd International Workshop on Location and the Web. New York: Association for Computing Machinery, 13-16.

DOI: https://doi.org/10.1145/1507136.1507141 


\section{Geographical Perspectives on Location for Location Based Services

\author{
Alistair J. Edwardes \\ Department of Geography \\ University of Zurich \\ Switzerland \\ +41446355256 \\ alistair.edwardes@geo.uzh.ch
}

"@ ACM, 2009. This is the
author's version of the work. It is
posted here by permission of
ACM for your personal use. Not
for redistribution. The definitive
version was published in
Proceedings of the Second
International Workshop on

\begin{abstract}
In this position paper the question of how location is employed in location based services (LBS) is considered. The importance of the notion of location is highlighted as a means of blurring the boundary between forms of experiences that are direct, and sensed in the environment, and those that are indirect, and learned from information. It is suggested that current methods for modeling location are limited by their lack of strong theoretical underpinning. To help bridge this gap the notions of Space, Place, and Region, from geographical theory, are proposed and implications of these for considering location in LBS outlined.
\end{abstract}

\section{Categories and Subject Descriptors}

H.3.5 [Online Information Services]: Web-based Services

\section{General Terms}

Human Factors, Theory, Design

\section{Keywords}

Place, LBS, Location Based Services, Location Modelling

\section{INTRODUCTION}

Bringing technology closer to people's apprehension of the world has long been a goal of contextual and pervasive computing in its various forms. Location based services (LBS) are an example of such a technology, which allow representations of the world to be brought side-by-side with individuals' engagement with it [1].

Location in such services is emphasised as both a means to scope contents geographically, and a way for information to be presented in context relevant ways. However, location has largely inherited a viewpoint from geo-spatial technologies that treats it as something objective, universal, static, and abstract. Whilst such a treatment provides a detachment appropriate for analysing geographic data, for LBS where the context is people and their direct engagement with the world, this position is far less tenable.

Permission to make digital or hard copies of all or part of this work for personal or classroom use is granted without fee provided that copies are not made or distributed for profit or commercial advantage and that copies bear this notice and the full citation on the first page. To copy otherwise, or republish, to post on servers or to redistribute to lists, requires prior specific permission and/or a fee.

LocWeb 2009, April 4, 2009 Boston, MA, USA.

Copyright 2009 ACM 978-1-60558-457-7/09/04...\$5.00.
Location is a fundamentally ambiguous term [3]. It refers not only to the continuously changing position of a person, but also their relation to the places, things and other people that interweave through space, time and scale. As such, location cannot easily be separated from the context in which it is made meaningful. Hence, location can be seen as combining both 'ego-centric' [2] and geographic factors making its definition problematic.

These observations suggest a theoretical gap in how location can best be presented and represented in LBS. This position paper attempts to navigate this gap by considering location in the light of geographic theory.

\section{LOCATION IN LBS}

Location-based services were born out of the configuration of a set of technologies that had reached a sufficient level of maturity, availability, affordability, usability, and interoperability, such that they could offer the potential to fundamentally change the way in which information is accessed and used in everyday life. Amongst these were positioning technologies [4][5] and in particular GPS. GPS had reached a point of commodification where reliable handheld receivers could be purchased universally at relatively little cost. These introduced the ingredient of location into the mobile information services that had arisen out of the convergence of other computing and communication infrastructures.

Initially, location was understood within these technologies to mean position. Through a common spatial reference system, point-based information could be inter-related, for example by Euclidean distance. This understanding of location has been found to be limited for many situations. For one thing, different positioning techniques have differing levels of precision and accuracy [6]. This affects the way the position can be related to other information and therefore constrains the types of services the technique can be used for [7]. Secondly, a large amount of geographic information is either not available or not relevant as points, for example addresses and postcodes, buildings and their functional parts, distributions of wildlife etc. Third, relationships based on point-to-point geometric measurement are hard pressed when it comes to considering the constraints and barriers of the underlying geographic fabric of the space or the human factors that are required to formulate location as a meaningful unit for organising behaviour and opportunities.

To address these issues location has increasingly come to be understood as position qualified in geographic terms. For 
example, by referencing it to a GIS database of features e.g. roads, addresses, cities etc. Hence, location can be seen to describe the geographic embedding that binds position and different forms of information together.

\subsection{Location Modelling}

Achieving a successful embedding means that the two domains (position and information) must be indexed by a shared frame-ofreference that unites the entities relevant to the user of an LBS (e.g. resources, services, people, places and events) with a model of locations where they can exist. These locations can be modelled in different ways that have been categorised as geometric, symbolic and semantic [8][9]. Geometric locations are distance neighbourhoods around a user's location, where the distance might be measured in different ways, e.g. radially or through a network. Symbolic locations are essentially addresses, often defined hierarchically. Examples are the location of a person within a building; e.g. which floor and which room they are in on that floor, and postal zones. Semantic locations use the semantic meaning of a zone that a person is in to define a context to their actions. For example if someone has stopped by a bus-stop they are probably interested in taking a bus. Semantic locations can also be defined by social relations e.g. the people who you are near. In this sense a location might be 'With Bob'.

What this classification obscures though is the fundamental differences in what location means and how it can be employed. These are determined not by variations in the way location is represented, but rather by differences in how location is understood at different times. Location as a 'thing', geometrically bounded, is a very different concept to location as a context for social interaction or location as a setting for different activities. As such location is really a form of, very localised, geographical knowledge created by the experience of the person using the device or the designer of a service communicating information.

Hence, consideration of how people interpret space is lacking, since the human in the service is still being abstracted to a position, a representation of space rather than an experience of space. In the latter sense, location is a reflexive relationship between people and their continuous perception and cognition of the environment. Seen as such a dynamic suggests location might benefit from a more thorough examination through the lens of geographic theory.

\section{MOBILE GEOGRAPHIES}

A conventional view is that geography is the study of space and place [10]. These seemingly simple categories underlie many of the differences among geographers both in terms of what they study and how they go about it. [11]. Place relates geography to human existence, experiences and interaction [12]. Whilst, a spatial perspective provides the means to think about and describe the world in a more detached logical way e.g. with geometry.

The significance of these attitudes to LBS arises because they need to mix different geographic perspectives in presenting useful services and information. This is highlighted by Longley [13] who notes, "The historical demarcation in psychological and behavioural geography between direct and indirect experience blurs when handheld devices are used as an adjunct to reality in the field."(p.114). That is, LBS bring side by side geographic knowledge about the world, such as maps, statistics and geographic information, and primary knowledge acquired directly through the senses.

LBS seek a far more intense and intimate relationship with the consumer, their interests, intentions and actions than other technologies. This forces a focus much more on the subjective experience of the user better accounted for through the notion of place. At the same time, LBS need to adopt an objective representational framework as a method of organisation for describing and reasoning about geo-spatial phenomena. In doing so, LBS draws on spatial tools and models essentially creates spaces. And so, a dichotomy between place and space emerges.

\subsection{Place}

Place has been described as a contested concept [14][15], in the sense that it defies any universal definition. Place is generally described in relation to the ways in which people make sense of "amorphous and intangible" space [12]. As noted by Tuan [17]; "What begins as undifferentiated space becomes place as we get to know it better and endow it with value." (p.6).

One of the quintessential ways in which people make sense of space is by naming it. When space is made meaningful in such a way the resulting places are often conceived of as objective features of a landscape, for example settlements in a gazetteer [16], and so place is thought of as being about things; discrete named locations in space. However, it is really the process of naming that has given meaning to the space and so more properly place emphasises the way of understanding rather than the thing.

Place seen in this way emerges from the geographical knowledge generated by the experiences and consciousness people have of the world. These can be based on very direct sensations, such as how somewhere looks and feels, by more emotional or cultural ties, such as growing up somewhere, or through dependencies people have to a place related to its particular affordances, for example being the only source of water in a desert.

\subsection{Space}

Geographic technologies deal with things - ontological representations and concrete models of spatial phenomena. Hence, their focus is more on how the world looks than what it means. The spatial perspective provides the framework to realize such a view allowing the analysis of intensities and arrangements of geographic phenomena. As such, geometry holds a privileged role, because it provides an effective apparatus to quantify, describe and analyse the world from scales and perspectives that cannot otherwise be apprehended directly. Since geometry may be described mathematically it is also ideally suited to encode data for representation in computers.

The result of this is that, for the most part in LBS, location is an essentially spatial concept. Space is represented absolutely using a spatial reference system that allows positions to be indexed, organised. This provides the most simple and straight-forward method for linking information and the user, since it can then be detached entirely from its material setting and co-related using only a distance metric. This is the model that has dominated location-based search in LBS, for example to answer questions in the form "Where is my nearest . . . ?" using a radial search propagated from the user's position. 


\subsection{Region}

Adjoint to the notions of space and place is often added that of region [18][19]. The relationship between the three concepts is not always clear, different authors having defined regions as spaces, or as sub- or super- concepts of place (c.f. Agrawal, 2004). Montello [18] suggest regions are a form of category and so a unit for cognition and language. The process of categorisation agglomerates entities based on shared properties meaning regions are qualitatively defined and often vague. Geographic regions describe regions of homogenous qualities in space but the vagueness of the processes often means their boundaries are imprecise. As a form of category, one way regions can be distinguished from places is that they are general classes whilst the former are specific instances. They allow geography to be communicated and compared as indirect experiences. For example, we can talk about urban and rural regions, or sub regions of these like central business districts, suburbs and docks, where a regional distinction has been made based on some defining characteristic such as the main industrial activity, relative location, or building type and density. In contrast, a place might belong to a region but it also carries individual and communal meanings. For example, Govan in Glasgow, Scotland can be seen as part of a working-class, industrial region, but as a place it is meaningful in terms of its history in the rise and fall of the ship building industry, the trade union movement etc.

\subsection{Discursive Displacement}

Curry [19] terms the process of employing one perspective to represent another, discursive displacement. It results in much of the ontological ambiguity amongst the three concepts space, place and region. Discursive displacement occurs most clearly when a spatial framework is imposed on perspectives of place and region and in doing so supposes a boundary that is not otherwise inherent in the way of thinking. The result can then be seen in the ongoing issue of how to define and represent fuzzy boundaries and imprecise regions. Equally it can be seen when places are described as regions (e.g. a neighbourhood) or regions as places (e.g. a nation). Likewise, in LBS, a spatial description of the position of a user is displaced as a location framed within the context of a place or region.

\section{IMPLICATIONS FOR LBS}

The key implication for LBS outlined here is that a model of location based on geometric primitives, such as simple $\mathrm{x}, \mathrm{y}$ positions or located toponyms, is not sufficient. This is because it fails to account for either the geography sensed by the user or the geography of the physical setting that they find themselves in.

\subsection{Place as geographic experience}

Place is perhaps the most important perspective in LBS because it introduces a human dimension to location and so helps to blur the boundary between direct and indirect experience. It is also probably the most neglected aspect to location in current LBS.

The main difficulty of place is the issue of how to represent it since many aspects of place emerge through people's subjective perceptions and experiences which change continuously over time. This means a spatial a priori representation of space is problematic. One way around this problem is for LBS to present spaces in such a way that users can create places themselves through their interactions in the environment and with the service.
For example, meaning is implicitly added to locations when they are named so allowing naming of locations and interaction with named places is a simple way of making locations more meaningful. Likewise, by considering how people sense and explore space, for example by analyzing the visibility of spaces, allows locations to be created as functions of perception and behaviour.

Such models will be particularly relevant to services that focus on human aspects in the definition of their user needs. For example, services answering questions like "What is this..?", "Where's my nearest...?", or "How do I get to..?" are better suited to models of location that are relevant to the interaction (e.g. locations as decision points) and movement (e.g. the transport network).

Location models using place do not need to rely on an underlying spatial representation. Instead, they can use description and narrative to characterize locations and guide users between them, an example of such a model is that of GUIDE [21].

\subsection{Region as categories for information}

Whilst place develops location from the immersed perspective of the person using a service, region allows location to consider the geographic qualities of the space in ways that are more sensitive to the properties of the information being served. In particular, when information being provided is not point based or when its spatial relevance is not distance based, the perspective of region can suggest geographically derived location units with which to index information [22]. Region then provides a spatio-semantic index to organize information by essentially extending the qualities of geographically defined locations to include those of the information being indexed.

To give an example, a LBS providing botanical information might not have available point based data on plant occurrences, since this sort of information is highly ephemeral and laborious to collect. Instead, it could a employ a model of location based on biographical units (e.g. soil) which the plant is related to. In this situation a user is more interested in the qualities (in terms of plants) of their location than particular instances where these can be found. Nearness is therefore more a general situational relevance than a direct distance. Other examples might relate to users wanting to know about the sorts of opportunities offered by a place in terms of entertainment or a somewhere to live. The sorts of questions that region locations are useful for are therefore more concerning qualities and characteristics, such as "What's around me...?" and "What can I find here?"

As with place, regions are not inherently spatial entities, and a regional model of location need not be spatially based. However, often their use in LBS does necessitate quantification which will often lead to problems in representing have vague and uncertain boundaries.

\subsection{Space in visualisation}

Space was highlighted here as a perspective that needs to be treated with some caution. It is problematic because it is sticky, in the sense that it can introduce a particular view point on how information should also be presented when this may not be fundamentally appropriate. However visually, the spatial view point is invaluable for presenting relatively static, descriptive information about geographic patterns and distributions that are 
largely independent of the particular situation of the user. For example, describing the layout of locations relative to one another in response to question of the form "Where can I find...?" In this case, the users own location may only be marginally relevant and rather they are interested in knowing about the patterns of locations remote to them.

More often, the role of space is in representing the other types of location so they can be effectively handled in a computational environment. Problems occur when the spatial perspective is overemphasized. For example, when location is modeled as a radial distance, regional and place-based perspectives are limited to a geometric substitute. Hence, care needs taking to ensure the spatial is operating in the background, underpinning the alternative perspectives rather than subsuming them.

\section{OPEN QUESTIONS}

The position adopted here was that three concepts; space, place and region not only represent different types of geographic abstractions for modelling and representing location, but they also constitute different perspectives that people use to structure and encode their knowledge and experiences of the world. Rather than draw any specific conclusions now I would like to close by presenting a set of questions that I would see as relevant for further discussion at this conference.

Are such theoretically informed models of location really required or are current geometric, symbolic and semantic models sufficient?

How can the issues of representing location with respect to the perspectives presented be tackled? Is there an overt concern with spatial representation of location and with its accuracy and precision?

In what context are different perspectives on location best employed? Can and should different perspectives be combined in location models?

\section{ACKNOWLEDGMENTS}

The research reported is supported by the project TRIPOD supported by the EC under contract No. 045335.

\section{REFERENCES}

[1] Armstrong, M. P. and Bennett, D. A. 2005. A Manifesto on Mobile Computing in Geographic Education, The Professional Geographer 57(4), 506-515.

[2] Meng, L. 2005. Egocentric design of map-based mobile services, The Cartographic Journal 42(1), 5-13.

[3] Schlieder, C.; Vögele, T. and Werner, A., 2001. Location modeling for intentional behavior in spatial partonomies, in Proceedings of Ubicomp 2001: Workshop on Location Modeling for Ubiquitous Computing, pp. 63-70.

[4] Roth, J., 2004. Data Collection, in J. Schiller \& A. Voisard, eds., Location-Based Services, Morgan Kaufmann Publishers, San Francisco, CA, pp. 175-205.

[5] Grejner-Brzezinska, D. 2004. Positioning and Tracking Approaches and Technologies, in H. A. Karimi \& A. Hammad, eds.,Telegeoinformatics, CRC Press, , pp. 69-106.

[6] Spinney, J. E. 2003. The Computer for the 21st Century. , Geography 88(4), 256-265.
[7] Mountain, D. and Raper, J. 2001. 'Positioning techniques for location-based services: characteristics and limitations of proposed solutions', Aslib Proceedings 53(10), 404-412.

[8] $\mathrm{Hu}, \mathrm{H}$. and Lee, D. 2004. Semantic location modeling for location navigation in mobile environment, in Proc. of the 2004 IEEE Intl. Conf. on Mobile Data Management (MDM'04), pp. 52-61.

[9] Hsieh, P. and Yuan, S. 2003. Dynamic semantic location modeling in mobile enterprise applications, in 'Proc. 5th Intl. Conf. on Electronic Commerce (ICEC '03)', ACM Press, New York, NY, USA, pp. 102-110.

[10] Fisher, P. and Unwin, D. 2005. Re-presenting Geographical Information Systems, in Peter Fisher \& David J. Unwin, ed.,'Re-presenting GIS', Wiley \& Sons, London, pp. 1-17

[11] Couclelis, H. 1992, Location, place, region, and space., in R. F. Abler; M. G. Marcus \& J. M. Olson, eds. ,'Geography's Inner Worlds', Rutgers University Press., New Brunswick, NJ, pp. 215-233.

[12] Relph, E. 1976). Place and Placelessness, Pion, London.

[13] Longley, P. A. 2004. Geographical Information Systems: on modelling and representation, Progress in Human Geography 28(1), 108-116.

[14] Agarwal, P. 2005. Ontological considerations in GIScience, Intl. J. of Geographical Information Science 19(5), 501-536.

[15] Cresswell, T. 2004. Place: A Short Introduction, Blackwell, Oxford.

[16] Hill, L. 2000. Core Elements of Digital Gazetteers: Placenames, Categories, and Footprints, in Proc. 4th European Conf. on Research and Advanced Technology for Digital Libraries (ECDL '00), Springer-Verlag, pp. 280-290.

[17] Tuan, Y. 1977. Space and Place: The Perspective of Experience, University of Minnesota Press.

[18] Montello, D. R. 2003. Regions in geography: Process and content., in M. Duckham; M. F. Goodchild \& M. F. Worboys, ed.,'Foundations of Geographic Information Science', Taylor and Francis., London, pp. 173-189.

[19] Curry, M. R. 2002. Discursive Displacement and the Seminal Ambiguity of Space and Place, in L. Lievrouw \& S. Livingstone, eds, 'The Handbook of New Media: Social Shaping and Consequences of ICT.', Sage Publications, London, pp. 502-517.

[20] Tversky, B. (2002), Places: points, planes, paths, and portions, in J. Slack \& E. van der Zee, ed.,'Representing direction in language and space', Oxford University Press., Oxford, pp. 132-144.

[21] Cheverst, K.; Davies, N.; Mitchell, K. and Friday, A. 2000, Experiences of developing and deploying a context-aware tourist guide: the GUIDE project, in 'Proc. 6th Intl. Conf. on Mobile Computing and Networking (MobiCom '00)', ACM Press, New York, USA, pp. 20-31.

[22] Edwardes, A.; Burghardt, D.; Dias, E.; Purves, R. \& Weibel, R., 2005, Geo-Enabling Spatially Relevant Data for Mobile Information Use and Visualisation., in K.-J. Li \& C. Vangenot, ed.,'Proc. 5th Intl. Workshop on Web and Wireless GIS, W2GIS 2005', Springer-Verlag, pp. 78-92. 